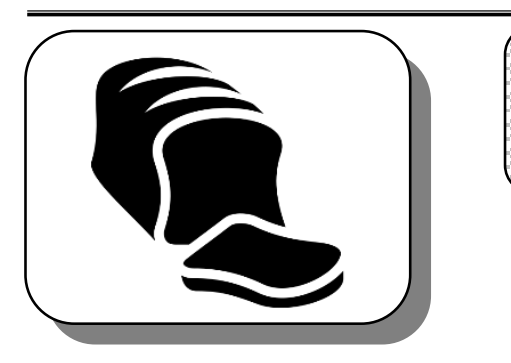

удК 636.61:637.07

DOI: 10.36718/1819-4036-2020-5-142-146

И. Н. Гришаева

\title{
СПОСОБ ПОЛУЧЕНИЯ ПАНТОВЫХ ЭКСТРАКТОВ НА УЛЬТРАЗВУКОВОЙ УСТАНОВКЕ ВЫСОКОЙ ИНТЕНСИВНОСТИ
}

\section{N. Grishaeva}

\section{THE WAY OF RECEIVING ANTLER EXTRACTS ON HIGH INTENSITY ULTRASONIC INSTALLATION}

Гришаева Ирина Николаевна - канд. биол. наук, вед. науч. сотр. лаб. переработки и сертификации пантовой продукции Всероссийского НИИ пантового оленеводства - отдела Федерального Алтайского научного центра агробиотехнологий, г. Барнаул. E-mail: wniipo@rambler.ru

Цель исследования - разработать способ получения пантовых экстрактов с применением ультразвуковой установки высокой интенсивности. Материалом для проведения экспериментов служили сырые и консервированные панты маралов. Лабораторные испытания провели на ультразвуковом технологическом anпарате серии «Волна», модель УЗТА-0,2/22ОМ. На первом этапе провели определение количества пантов, необходимого для достижения раствором лечебно-бальнеологической концентрации, сырые - в дозе 0,8; 1,0; 1,5 г/л и консервированные - в дозе 0,6; 0,68; 0,87; 1,2 г/л при разной температуре ультразвуковой экстракции 45; 55; 65; $75{ }^{\circ} \mathrm{C}$. Установление биологической активности пантового водного экстракта проводили в соответствии с методикой по определению показателя экстинции, который должен быть в диапазоне от 0,12 до 0,46. Качество экстракции оценивали по выходу биологически активных веществ путем определения сухого остатка. По результатам исследования установили необходимую массу загрузки, например применение 1,0 2/л сырых и 0,6-0,68 2/л консервированных пантов марала в течение 45-60 мин позволяет получить раствор лечебно-бальнеологической концентрации. Второй этап исследования был посвящен
Grishaeva Irina Nikolaevna - Cand. Biol. Sci., Leading Staff Scientist, Lab. of Processing and Certification of Antler Production, All-Russia Research Institute of Antler Reindeer Breeding - Branch of Altai Federal Scientific Center of Agrobiotechnologies, Barnaul. E-mail: wniipo@rambler.ru

изучению качественных показателей ультразвуковой экстракции путем определения выхода сухих веществ. Установлен достоверно высокий выход сухих веществ при экстракции сырых пантов маралов и массе загрузке 1,0 г/л $55,6 \%(p<0,01)$. Максимальные значения показателя при экстракции консервированных пантов получены при загрузке 0,68 г/л и температуре экстракции $75{ }^{\circ} \mathrm{C}$. Сравнительная оценка выхода сухих веществ при ультразвуковой экстракции пантов показала более высокое извлечение биологически активных веществ из сырого сырья. Комплексный анализ, проведенньй при апробации ультразвукового оборудования высокой интенсивности, показал получение пантового водного экстракта, соответствующего лечебно-бальнеологической концентрации при массе загрузке 1,0 г/л сырых пантов, времени экспозиции 45 мин и температуре $75^{\circ} \mathrm{C}$.

Ключевые слова: панты, марал, пантовые ванны, показатель экстинции.

The research objective was to develop the way of receiving antler extracts by application of ultrasonic installation of high intensity. As the material for carrying out the experiments crude and canned maral velvet antlers were used. Laboratory tests were carried 
out on ultrasonic technological device of the "Volna" series,UZTA-0.2/22-OM model. At the first stage the definition of the quantity of maral antlers, necessary for the achievement of the solution of medical and balneological concentration was carried out, crude in a dose 0.8; 1.0; $1.5 \mathrm{~g} / \mathrm{l}$ and preserved - in a dose $0.6 ; 0.68 ; 0.87 ; 1.2 \mathrm{~g} / \mathrm{l}$ at different temperature of ultrasonic extraction $45 ; 55 ; 65 ; 75^{\circ} \mathrm{C}$. The establishment of biological activity of antler water extract was carried out according to the technique for the definition of the indicator of an extinction which had to be in the range from 0.12 to 0.46 . The quality of extraction was estimated on the exit of biologically active agents by the definition of dry rest. By the results of the research the necessary mass of loading was established, for example application of $1.0 \mathrm{~g} / \mathrm{l}$ of crude and 0.6-0.68 g/l of canned maral velvet antlers within 4560 minutes allowed receiving the solution of medical and balneological concentration. The second investigation phase was devoted to studying the quality indicators of ultrasonic extraction by the definition of the exit of solids. Authentically high exit of solids at the extraction of crude maral antlers, and weight was established to loading of $1.0 \mathrm{~g} / \mathrm{l}-55.6 \%(r<0.01)$. The maximum values of the indicator at the extraction of canned maral velvet antlers were received during the loading of $0.68 \mathrm{~g} / \mathrm{l}$ and the temperature of extraction equal to $75{ }^{\circ} \mathrm{C}$. Comparative assessment of the exit of solids at ultrasonic extraction of antlers showed higher extraction of biologically active agents from crude raw materials. The complex analysis carried out at the approbation of ultrasonic equipment of high intensity showed receiving antler water extract corresponding to medical and balneological concentration with the weight loading of $1.0 \mathrm{~g} / \mathrm{l}$ of crude antlers, the time of exposition equal to 45 minutes and the temperature of $75^{\circ} \mathrm{C}$.

Keywords: antlers, deer, antler bath, extinction indicator.

Введение. Мараловодческая отрасль России требует от научного сообщества поиска новых способов и технологических решений, которые способны обеспечить рынок конкурентоспособными сельскохозяйственными товарами, снизить объем экспортных поставок продукции пантового оленеводства в страны Юго-Восточной Азии. Создание новых продуктов переработки сырья маралов, соответствующих международным стандартам и требованиям мирового рынка, позволит обеспечить продовольственную безопасность страны.
Разработка современных способов извлечения из сырья всех биологически активных веществ может интенсифицировать процесс, сократить затраты на приготовление, хранение раствора. Одним из наиболее эффрективных способов интенсификации является воздействие ультразвуковыми колебаниями высокой интенсивности, позволяющими ускорять массообменные процессы, увеличивать выход получаемых продуктов, повышать их качество [1].

Анализ доступной современной научнотехнической и патентной литературы показал, что пантовые водные экстракты в основном производятся как побочная продукция в результате высокотемпературного процесса консервирования пантов на маральниках или с применением высокотемпературных экстракторов в санаториях. Именно в процессе варки происходит естественный переход определенной части водорастворимых веществ в горячую воду. Таким образом, полученная варочная вода представляет собой пантовый водный экстракт (ВЭ), содержащий комплекс биологически активных веществ, выделенных из кожного покрова и сердцевины пантов. На современном этапе контроль за составом пантового экстракта можно осуществить только с применением методики В. В. Александрова по коэфффициенту экстинции, но в горных условиях такие измерения зачастую отсутствует. Поэтому применение ультразвукового оборудования высокой интенсивности с заданными параметрами работы может позволить получать необходимые пантовые экстракты.

Цель исследования: разработать способ получения пантовых экстрактов с применением ультразвуковой установки высокой интенсивности.

Материал и методы исследования. Исследование проводилось во Всероссийском научноисследовательском институте пантового оленеводства ФГБНУ ФАНЦА в 2018-2019 гг.

Материалом служили сырые и консервированные панты маралов.

Апробация нового ультразвукового технологического аппарата серии «Волна», модель УЗТА-0,2/22-ОМ, для экстракции основной продукции пантового оленеводства включала в себя лабораторные испытания установки с целью получения пантового водного экстракта. Для определения необходимого количества пантов применяли следующие навески: 0,8, 1,0; 1,5 г/л сырых замороженных и 0,6; 0,68; 0,87; 1,2 г/л консервированных пантов марала. Определение оптимальных параметров ультразвуковой 
экстракции осуществляли в температурных режимах $45,55,65,75^{\circ} \mathrm{C}$ с одновременной оценкой показателя экстинции каждые 5 мин на протяжении 14.

Коэффрициент экстинции определяли согласно методике В.В. Александрова, показатель экстинции для определения биологической активности пантового водного раствора (ВЭ) - по средству так называемого пант-эквивалента (указывается активность ВЭ относительно активности пантокрина). В соответствии с методикой показатель экстинции пантового водного раствора от 0,12 до 0,23 соответствует лечебнобальнеологической концентрации, а выше 0,46 является токсической для организма [3].

Исследование компонентного состава пантового водного экстракта, полученного методом ультразвуковой экстракции в разных температурных режимах, осуществляли путем определения выхода биологически активных веществ из сырья по количеству сухого остатка (ГОСТ 31640-2012) [4].

Результаты исследования. С целью определения оптимального количества пантового сырья на первом этапе осуществили экстракцию 0,8 г сырых пантов марала в 1 л воды при температуре $45,55,65,75^{\circ} \mathrm{C}$. Значения результатов исследования показали, что при температуре $45^{\circ} \mathrm{C}$ через $45-55$ мин ультразвуковой экстракции пантовый водный экстракт достигает пороговых значений, но не позволяет получить полноценный лечебный раствор даже при температуре $75^{\circ} \mathrm{C}$ и времени 60 мин.

При экстракции 1,0 г/л сырых пантов маралов наблюдалось насыщение раствора биологически активными веществами при температуре $45-55^{\circ} \mathrm{C}$, через 5 мин значение достигло лечебно-бальнеологической концентрации, и только через 40 мин экстракт становился токсичным (рис. 1).

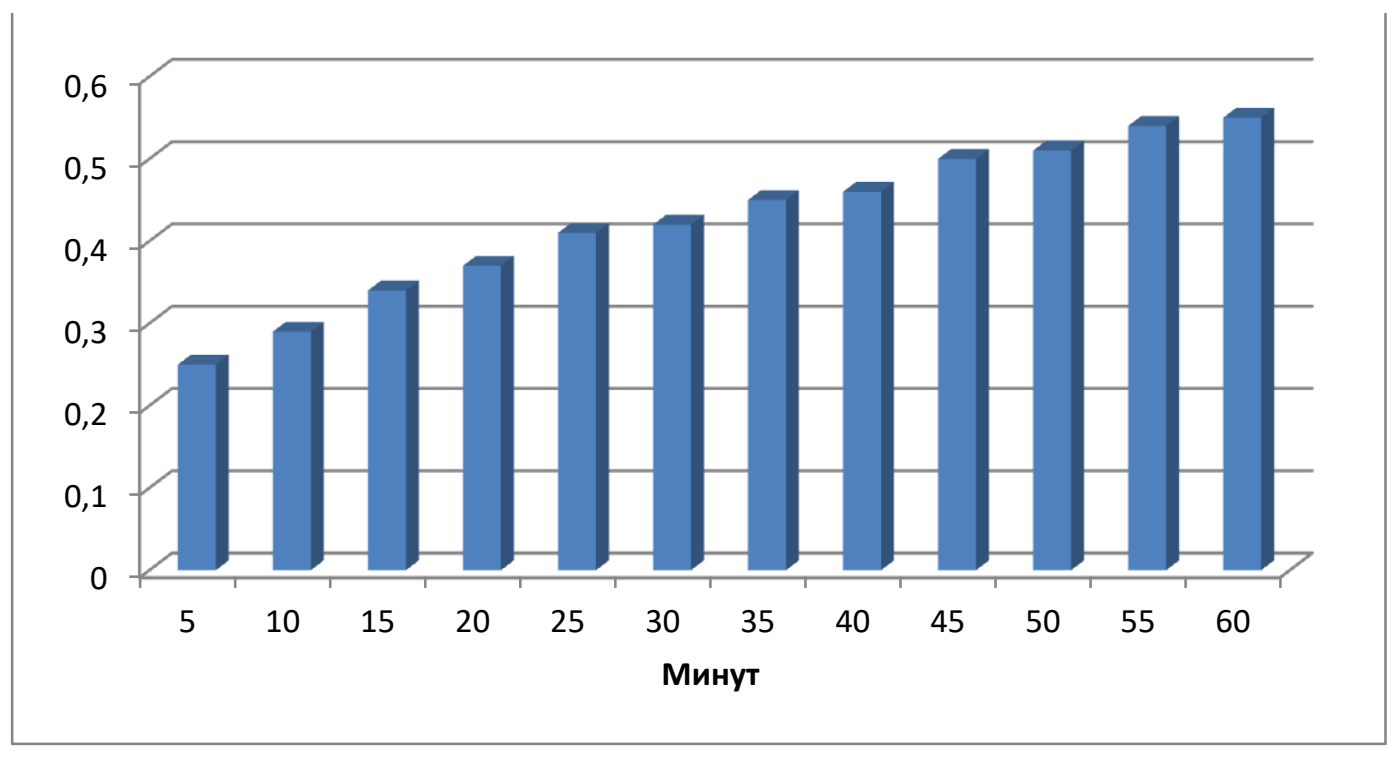

Puc. 1. Динамика коэфффициента экстинции при температуре $55^{\circ} \mathrm{C}$

Увеличение массы пантов до 1,5 г/л приводит к очень быстрому набору биологически активных веществ экстрактом. Так, при температуре $65-75^{\circ} \mathrm{C}$ концентрация становится токсичной уже через 10 мин, при этом в пантах еще высока концентрация полезных веществ.

Экстракция консервированных пантов маралов в дозе 0,6 г/л показала значение 0,12士0,08, соответствующее лечебно-бальнеологической концентрации при температуре $45^{\circ} \mathrm{C}$ и времени
15 мин. Повышение температуры до $75^{\circ} \mathrm{C}$ при такой дозировке позволяет получать экстракт, в течение 1 ч не превышающим токсического значения (рис. 2).

Увеличение массы пантов до 0,68 г/л в разных температурных режимах позволяет получать пантовый экстракт, соответствующий требованиям в течение 45-50 мин, далее раствор становится токсичным. 


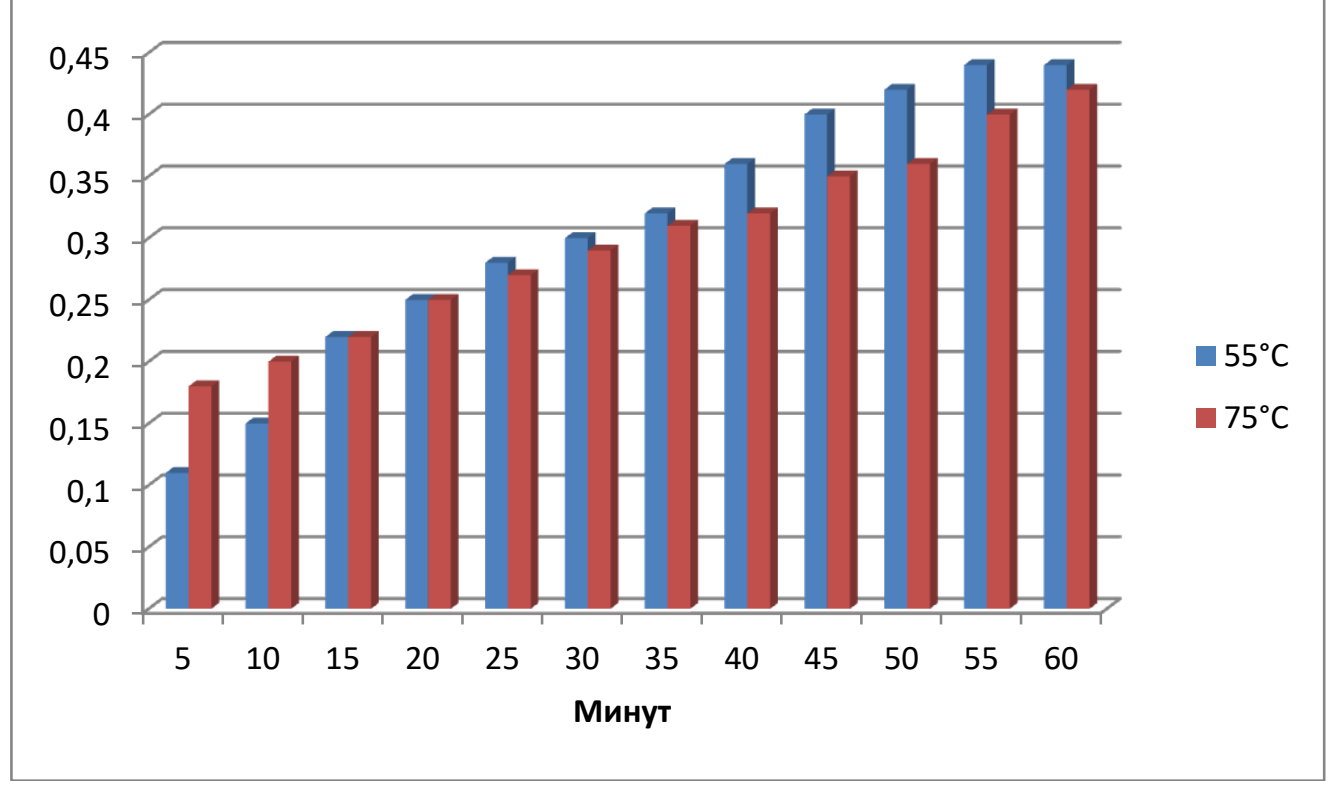

Puс. 2. Динамика коэфффициента экстинции при температуре $55,75^{\circ} \mathrm{C}$

Таким образом, при сравнении значений показателя экстинции ультразвуковой экстракции установлено, что оптимальным количеством является 1,0 г/л сырых (время экспозиции от 5 до 45 мин) и 0,6-0,68 г/л консервированных пантов марала (в течение 15-50 мин) в зависимости от температуры (рис. 3).

Для определения степени извлечения биологически активных веществ из пантов при ультразвуковой экстракции, а, как известно, это до $60 \%$ органических веществ, провели серию опытов по определению количества сухого остатка (рис. 4).
При анализе количества сухого вещества при экстракции сырых пантов маралов установлено, что максимальный выход получается при дозировке 1,0 г/л $(55,6 \%, p<0,01)$ при температуре $75{ }^{\circ} \mathrm{C}$. Увеличение массы загрузки до 1,5 г/л снижает качество экстракции и сокращает извлечение биологически активных веществ. Оценка ультразвуковой экстракции консервированных пантов свидетельствует, что лучшее извлечение БАВ в пантовый экстракт при загрузке 0,68 г/л и температуре экстракции $75^{\circ} \mathrm{C}$.

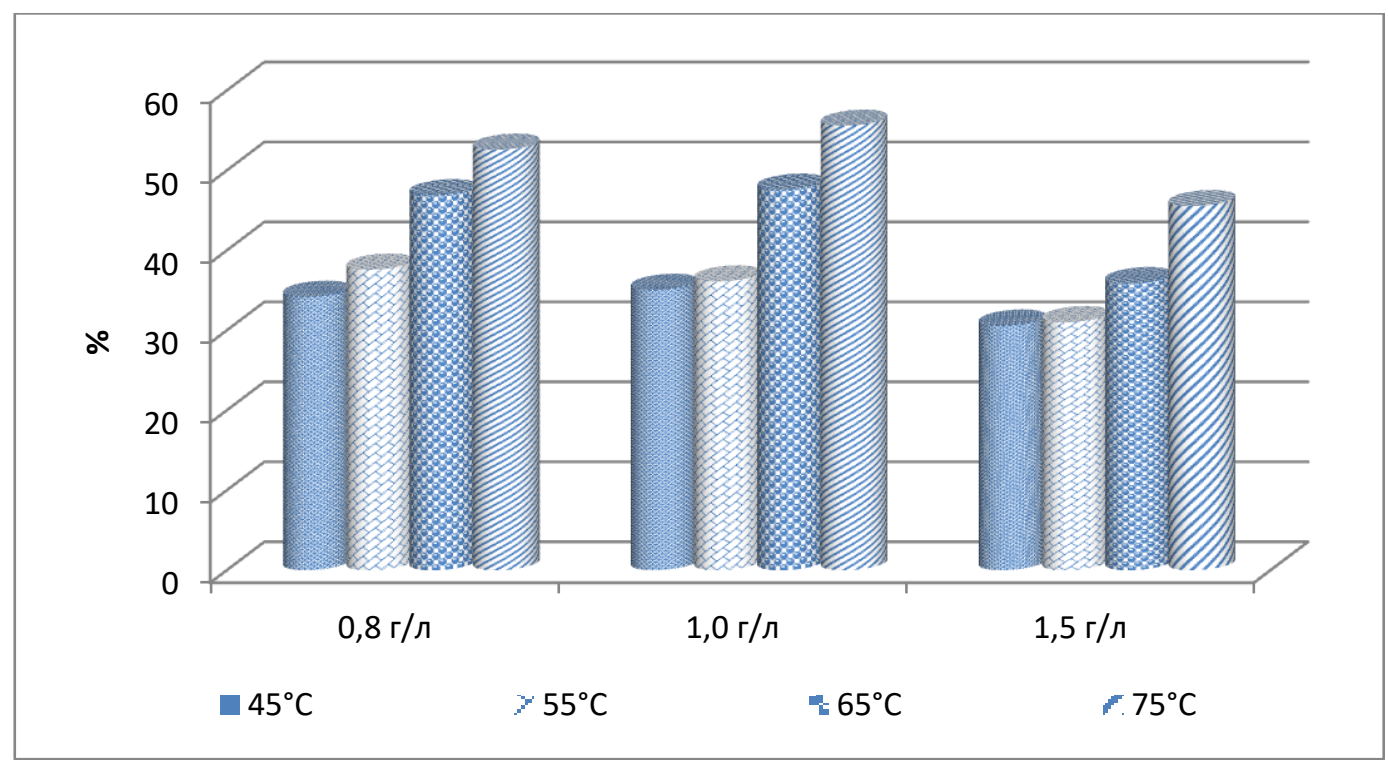

Рис. 3. Количество сухого вещества при ультразвуковой экстракции сырых пантов марала 


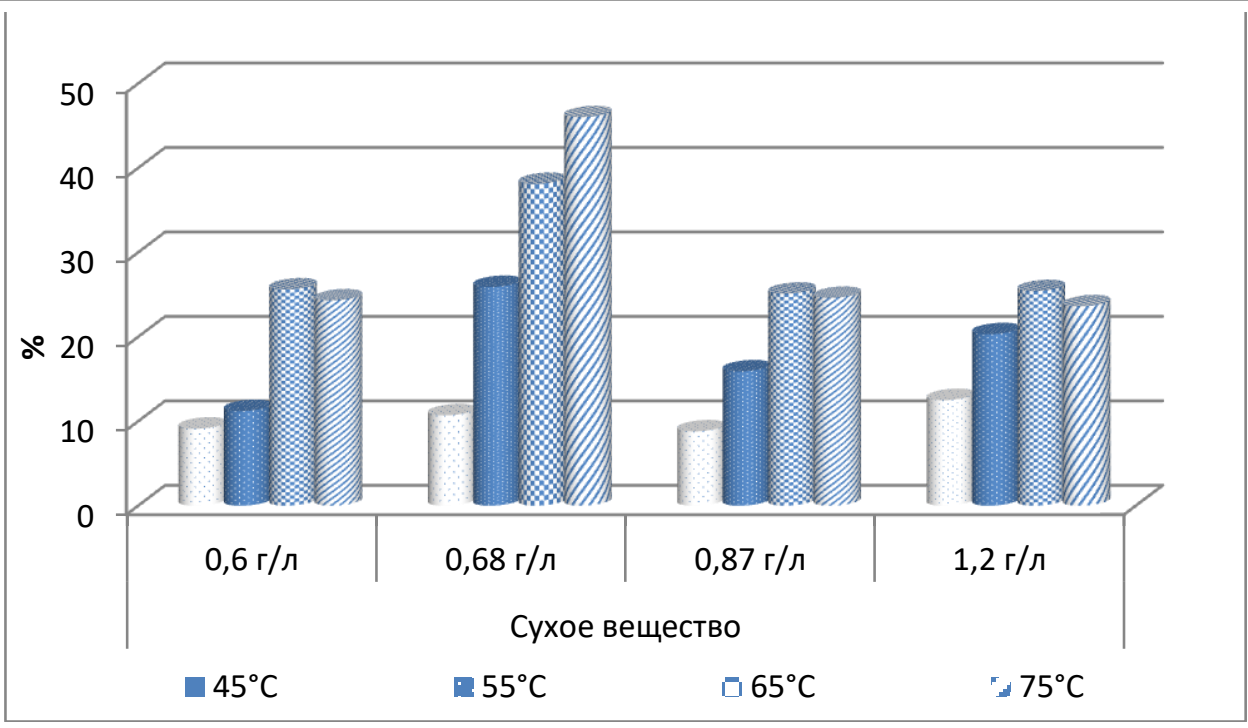

Pис. 4. Количество сухого вещества при ультразвуковой экстракции консервированных пантов марала

Данные рисунков 3 и 4 свидетельствуют, что применение ультразвукового оборудования позволяет из сырых пантов марала получать более высокий выход в экстракт биологических активных веществ (55,6\%), чем из консервированных (44,8\%). Максимальный выход отмечается при температуре $75{ }^{\circ} \mathrm{C}$, загрузка пантов подтверждает результаты изучения показателя экстинции.

Выводы. По результатам лабораторных исследований пантовых водных экстрактов, полученных на лабораторной ультразвуковой установке высокой интенсивности «Волна» УЗТА0,2/22ОМ, установлено, что оптимальным количеством сырого панта для получения показателя экстинции от 0,12 до 0,46 является загрузка 1,0 г/л, при этом оптимальная температура экстракции должна соответствовать $75^{\circ} \mathrm{C}$, время экспозиции 45 мин. Такие параметры экстракции пантов способствуют выходу сухих веществ $55,6 \%$.

\section{Литература}

1. Луницын В.Г. Производство, переработка и биохимический состав продукции пантового оленеводства. Барнаул, 2008. 294 с.

2. Белова А.Б., Можаев В.В., Левашов А.В. Взаимосвязь фризико-химических характе- ристик органических растворителей с их денатурирующей способностью по отношению к белкам // Биохимия. 1991. Т. 56, вып. 11. C. 1923-1945.

3. Александров В.В., Азаев Ю.Л., Биденко И.А. и др. Оздоровительно-профилактические медицинские технологии применения продуктов пантового оленеводства: учеб. пособие. Барнаул, 2004. 67 c.

4. ГОСТ 31640-2012. Корма. Методы определения сухого вещества. М., 2012.

\section{Literatura}

1. Lunicyn V.G. Proizvodstvo, pererabotka i biohimicheskij sostav produkcii pantovogo olenevodstva. Barnaul, 2008. $294 \mathrm{~s}$.

2. Belova A.B., Mozhaev V.V., Levashov A.V. 'Vzaimosvjaz' fiziko-himicheskih harakteristik organicheskih rastvoritelej $s$ in denaturirujushhej sposobnost'ju po otnosheniju k belkam // Biohimija. 1991. T. 56, vyp. 11. S. 1923-1945.

3. Aleksandrov V.V., Azaev Ju.L., Bidenko I.A. i dr. Ozdorovitel'no-profilakticheskie medicinskie tehnologii primenenija produktov pantovogo olenevodstva: ucheb. posobie. Barnaul, 2004. $67 \mathrm{~s}$.

4. GOST 31640-2012. Korma. Metody opredelenija suhogo veshhestva. M., 2012. 